\title{
Assessing Motivational Stages and Processes of Change for Weight Management Around Bariatric Surgery: a Multicenter Study
}

\author{
Albert Lecube $^{1,2}$ (D) Enric Sánchez ${ }^{1}$ - Ana Andrés ${ }^{3} \cdot$ Carmina Saldaña $^{4} \cdot$ Maria José Morales ${ }^{5}$ - Alfonso Calañas ${ }^{6}$. \\ Inka Miñambres ${ }^{7}$ - Silvia Pellitero ${ }^{2,8}$ • Fernando Cordido ${ }^{9}$ • Marta Bueno ${ }^{1}$ • Assumpta Caixàs ${ }^{10}$ • Nuria Vilarrasa ${ }^{2,11}$ • on \\ behalf of the Obesity Group of the Spanish Society of Endocrinology and Nutrition (GOSEEN)
}

(C) Springer Science+Business Media, LLC, part of Springer Nature 2019

\begin{abstract}
Introduction/Purpose The assessment of the patients' motivation as a predictor of behavioral change via five stages (precontemplation, contemplation, preparation, action, and maintenance) and four processes (emotional re-evaluation, weight management actions, environmental restructuring, and weight consequences evaluation) of change.

Materials/Methods A total of 542 participants (251 waiting for bariatric surgery (BS), 90 undergoing BS, and 201 controls) completed the Stages (S-Weight) and Processes (P-Weight) of Change in Overweight and Obese People questionnaires in a multicenter cross-sectional study.

Results A higher percentage of subjects seeking BS (31.7\%) were in the action stage $(16.7 \%$ of post-BS patients, $p<0.001$; $14.9 \%$ of controls, $p<0.001)$. The referred body mass index $(\mathrm{BMI})$ reduction was higher in subjects in active stages $(3.6 \pm 4.4 \mathrm{~kg} /$ $\mathrm{m}^{2}$ in maintenance versus $1.4 \pm 1.4 \mathrm{~kg} / \mathrm{m}^{2}$ in contemplation, $\left.p<0.001\right)$. In the P-Weight questionnaire, patients looking for BS scored significant higher in the four processes of change than controls. In addition, a positive and significantly correlation between BMI and the four processes was observed. In the stepwise multivariate analysis, BMI and the S-Weight allocation were constantly associated with the four processes of change.

Conclusion Obesity is accompanied by a modifying behavioral stage, suggesting that subjects before BS are seriously thinking about overcoming excess weight. To identify subjects on the waiting list for BS who will be more receptive to weight lost interventions remains a challenge.
\end{abstract}

Keywords Bariatric surgery $\cdot$ Motivation stages $\cdot$ Obesity $\cdot$ Processes of change $\cdot$ Weight loss

Albert Lecube

alecube@gmail.com

1 Endocrinology and Nutrition Department, University Hospital Arnau de Vilanova, Obesity, Diabetes and Metabolism Research Group (ODIM), IRBLleida, University of Lleida, Av. Rovira Roure 80, 25198 Lleida, Catalonia, Spain

2 Centro de Investigación Biomédica en Red de Diabetes y Enfermedades Metabólicas Asociadas (CIBERDEM), Instituto de Salud Carlos III (ISCIII), Madrid, Spain

3 Faculty of Psychology, Education Sciences and Sport Blanquerna, Universitat Ramon Llull, Blanquerna, Barcelona, Catalonia, Spain

4 Department of Clinical Psychology and Psicobiology, Institut de Neurociències, Universitat de Barcelona, Barcelona, Catalonia, Spain

5 Endocrinology and Nutrition Department, Complexo Hospitalario Universitario de Vigo, Vigo, Galicia, Spain
6 Endocrinology and Nutrition Department, Hospital Universitario Reina Sofia, Córdoba, Andalucía, Spain

7 Endocrinology and Nutrition Department, Hospital de la Santa Creu i Sant Pau, Universitat Autònoma de Barcelona, Barcelona, Catalonia, Spain

8 Endocrinology and Nutrition Department, University Hospital and Health Science Research Institute Germans Trias i Pujol, Badalona, Catalonia, Spain

9 Department of Endocrinology, Hospital Universitario A Coruña, A Coruña, Galicia, Spain

10 Endocrinology and Nutrition Department, Hospital Universitari Parc Taulí, Sabadell, Catalonia, Spain

11 Endocrinology and Nutrition Department, Hospital Universitari de Bellvitge-IDIBELL, L'Hospitalet de Llobregat,

Barcelona, Catalonia, Spain 


\section{Introduction/Purpose}

The prevalence of obesity has rapidly increased during the last three decades and has become one of the major public health problems in the Western world, with enormous physical, social, economic, and psychological repercussions $[1,2]$. This result may be related to the lack of efficacy of the non-invasive weight-loss approach to adult obesity [3, 4]. In fact, diet, exercise, and behavioral intervention have a very high long-term failure rate as body weight appears to be physiologically defended through hormonal, metabolic, genetic predisposition, and neural factors [5]. In addition, an adaptive decrease in resting metabolic rate together with an increase in desire for fatty foods follows weight loss $[6,7]$. Therefore, the $95 \%$ of people who try to lose weight regain and or even increase their weight within a period of 5 years after dietetic, pharmacological, or behavioral treatments [8]. Altogether, successful longterm weight managing still depends on the ability of individuals with obesity to change their behavior patterns. However, many patients find it extremely difficult to initiate and maintain such changes, especially with respect to diet and exercise. Similarly, the $20-25 \%$ of the subjects with obesity undergoing bariatric surgery (BS) may have an inadequate weight and metabolic response [9, 10].

How to identify subjects with poorer responses to weightloss interventions is still a challenge, both for the physician and for the Health Administration. After identifying patients who will fail to lose the expected amount of weight, physicians may dedicate more aggressive intervention to these subjects in which all efforts are needed to reduce disease severity. Faced with this unpromising situation, the possibility of tailoring interventions and enhance results in the context of weight management according to the patient's motivation has been pointed out in several studies [11, 12]. In this way, the transtheoretical model (TTM) recommends assessing two interrelated dimensions for the adequate assessment of behavioral modification: stages of change and processes of change [13]. The 1980s was the decade when TTM was proposed as useful framework for enhancing the success of behavior modification interventions for smoking cessation setting [14-16]. But it was not until the late 1990s that it was considered to apply the TTM also for the weight management [17-19].

"Stages of change" represent the temporal, motivational, and constancy aspects of change, that range from precontemplation ("At the moment I'm not doing anything to lose weight and I have no intention of doing anything over the next 6 months") to maintenance ("I've been making an effort taken to maintain my weight, by dieting and/or exercising, for more than 6 months") [20]. On the other hand, four "processes of change" (emotional re-evaluation, weight management actions, environmental restructuring, and weight consequences evaluation) identify the way in which people use overt and covert activities when they try to modify problem behaviors related to weight management [21]. It has been formerly recognized that progression through stages of change is partially due to activation of processes of change and explain the acquisition of healthy behaviors such as physical activity, eating patterns, or weight management [22, 23]. Gillison et al. in a pilot study including 108 participants with a mean BMI at baseline of $32.7 \pm 3.1 \mathrm{~kg} / \mathrm{m}^{2}$, showed how processes of change were found to mediate significant positive impacts in weight loss and fiber consumption after 4 and 12 months of intervention [23]. Altogether, stages and processes of weight management appear as a powerful predictor of behavior change, positioning their assessment as an important weight-management tool.

Two specific questionnaires to measure stages (S-Weight) and processes (P-Weight) of change in the setting of weight management have been developed and validated in Spanish and English [20, 24, 25]. However, there is no clinical data about the potential relationship between both questionnaires and weight in patients awaiting BS and in patients who have undergone bariatric procedures. To delve further into this relationship, we designed a multicenter cross-sectional study to evaluate stages and processes of change in a clinical sample of subjects with morbidly obesity before surgery, patients who lost weight post-BS, and controls without obesity.

\section{Materials/Methods}

\section{Study Design and Participants}

A total of 542 subjects were enrolled in the study between September 2015 and June 2017, and three groups were welldefined. The first one was recruited from the obesity units of the hospitals and included 251 subjects that were on the waiting list for BS at the time of their regular visits. All participants had successfully passed the psychological evaluation included in the BS protocol before proposing to participate in the study. The second group was formed by 90 patients who had undergone BS at least 18 months prior the study evaluation. The third set of patients involved 201 subjects without obesity (BMI $<30 \mathrm{~kg} / \mathrm{m}^{2}$ ), that were matched by age and sex with subjects in the obesity group; it was an opportunistic sample including family and companions of the previous two groups, and staff from the seven health centers. Inclusion criteria to participate in this study were age at least 18 years old, absence of alcohol or sedative abuse, and nonappearance of active malignancy.

The main clinical and sociodemographic characteristics (educational level, incomes, marital status, and weight satisfaction) of each group are shown in Table 1. The difference between the maximum weight reported by participants and the 
Table 1 The main clinical, anthropometric, social, and psychological characteristics of the three groups assessed in the study

\begin{tabular}{lllll}
\hline & $\begin{array}{l}\text { Obesity } \\
\text { group }\end{array}$ & $\begin{array}{l}\text { Bariatric } \\
\text { surgery group }\end{array}$ & $\begin{array}{l}\text { Control } \\
\text { group }\end{array}$ & $p$ \\
\hline$N$ & 251 & 90 & 201 & - \\
Age (years) & $46.8 \pm 10.2$ & $49.0 \pm 9.0$ & $47.8 \pm 10.1$ & 0.171 \\
Women, $n(\%)$ & $176(70.1)$ & $70(77.8)$ & $140(69.7)$ & 0.132 \\
BMI $\left(\mathrm{kg} / \mathrm{m}^{2}\right)$ & $43.0 \pm 7.7$ & $31.1 \pm 5.3$ & $25.0 \pm 2.9$ & $<0.001$ \\
Highest BMI $\left(\mathrm{kg} / \mathrm{m}^{2}\right)$ & $46.9 \pm 8.8$ & $50.6 \pm 6.9$ & $26.9 \pm 3.6$ & $<0.001$ \\
Change in BMI $\left(\mathrm{kg} / \mathrm{m}^{2}\right)$ & $3.5 \pm 4.5$ & $19.9 \pm 6.6$ & $1.9 \pm 1.7$ & $<0.001$ \\
Higher education, $n(\%)$ & $29(11.6)$ & $13(14.4)$ & $88(43.8)$ & $<0.001$ \\
Married, $n(\%)$ & $130(51.8)$ & $41(45.6)$ & $103(51.2)$ & 0.721 \\
Gross income $>36,000 €, n(\%)$ & $19(7.6)$ & $4(4.4)$ & $72(35.8)$ & $<0.001$ \\
No dieting during the previous 12 months, $n(\%)$ & $44(17.5)$ & $28(31.1)$ & $127(63.2)$ & $<0.001$ \\
Weight satisfaction: "From slightly to very & $183(72.9)$ & $10(11.1)$ & $71(35.3)$ & $<0.001$ \\
\multicolumn{1}{c}{ dissatisfied with my current weight", $n(\%)$} & & & & \\
\hline
\end{tabular}

Data are expressed as mean \pm standard deviation or $n(\%)$. BMI, body mass index; "Change in BMI", the difference between the maximum BMI reported by the subject and the current BMI current weight was calculated in addition to the change in BMI (subtracting maximum BMI from current BMI of the all groups).

\section{Instruments: S-Weight and P-Weight Questionnaires}

Participants completed the Spanish version of the Stages of Change in Overweight and Obese People (S-Weight) and the Processes of Change in Overweight and Obese People (PWeight) without any time limitation. Those on the waiting list for BS and those who had undergone BS completed both questionnaires during a routinely outpatient visit [26]. The $\mathrm{S}$-Weight is a questionnaire that consists of five mutually exclusive items that aim to allocate participants to one of the five stages of change for weight management proposed by the TTM $[13,25]$. Participants were asked to choose the response that best corresponded to their current situation with respect to losing weight: (1) pre-contemplation; (2) contemplation ("At the moment I'm not doing anything to lose weight but I'm thinking about doing something over the next 6 months"); (3) preparation ("During the last year I haven't done anything to lose weight but I'm planning to do something over the next 30 days"); (4) action ("I've been making an effort taken to lose weight, by dieting and/or exercising, for less than 6 months"); and (5) maintenance.

The P-Weight is a 34-item questionnaire developed to assess four processes of change in weight management [21, 24]: (1) emotional re-evaluation (EmR, 13 items), (2) weight management actions (WMA, 7 items), (3) environmental restructuring (EnR, 5 items), and (4) weight consequences evaluation (WCE, 9 items). The answer to each item range from 1 (strongly disagree) to 5 (strongly agree), with none of the items being reverse scored. Scores for each one of the four processes were calculated by summing the scores obtained on items belonging to the same subscale, in which lower scores reflect no use of a given process of change and higher scores reflect the full use of that process [13]. To make scores from the different subscales comparable, these scores are transformed on a scale ranging from 0 to 100 .

\section{Statistical Analysis}

Statistical analyses were performed using IBM SPSS Statistics for Windows, Version 20.0 (Armonk, NY: IBM Corp). All variables followed a normal distribution according to the Shapiro-Wilk test, so data were expressed as the mean \pm standard deviation. Comparisons between groups were performed using analysis of variance and the Student's $t$ test for continuous variables, and the $\chi 2$ test for categorical variables. The relationship between the continuous variables was examined with Pearson's linear correlation test. Four stepwise multivariate regression analyses were used to explore the variables independently related to the processes of change (EmR, WCE, WMA, and EnR). Age, gender, BMI, education, gross incomes, and weight satisfaction were the dependent variables. Significance of results was considered with $p<0.05$.

\section{Results}

Participants on the waiting list for BS and post-BS showed a higher prevalence of unfinished primary school than individuals without obesity $(22.3 \%$ and $30.0 \%$, respectively, versus $7.9 \% ; p<0.001$ for both comparisons) and a gross income $\leq$ $18.000 €$ per year $(44.2 \%$ and $52.2 \%$, respectively, versus $24.4 \% ; p<0.001$ for both comparisons). In addition, both groups were also less satisfied with their current weight than subjects without obesity (Table 1). 
When the five stages of change for weight management (S-Weight questionnaire) were assessed, patients seeking BS placed themselves mostly in the action $(31.7 \%)$ and the maintenance $(43.8 \%)$ stages. The percentage of subjects with morbid obesity in the action stage was significantly higher than the percentage observed among postBS patients and subjects without obesity (16.7\%, $p<0.001$ and $14.9 \%, p<0.001$ ) (Fig. 1). This data agrees with the fact that subjects on the waiting list for BS confirmed the initiation of more diets during the previous year than the other two groups (between one and three diets: $61.4 \%$ in subjects looking for BS, $35.5 \%$ after BS, and $25.9 \%$ in individuals without obesity; $p=0.003$ for both comparisons). On the other hand, the $56.7 \%$ who had undergone BS were in the maintenance stage and were working to prevent relapse and consolidate the gains attained during the action (43.8\% in subjects with obesity and 22.9 in participants without obesity; $p \leq 0.001$ for both comparisons) (Fig. 1). Conversely, individuals without obesity were mainly allocated to the precontemplation stage, expressing no intention to change their behavior in the future; this result was significantly higher that the percentage detected in subjects with obesity $(39.9 \%$ versus $1.6 \%, p<0.001)$.

When the difference between the maximum and the current BMI was assessed in subjects on the waiting list for BS, BMI decrement was higher in subjects who claimed to be in the active stages (action, $3.5 \pm 4.0 \mathrm{~kg} /$ $\mathrm{m}^{2}$; maintenance, $3.6 \pm 4.4 \mathrm{~kg} / \mathrm{m}^{2}$ ) than in those in the earlier stages (pre-contemplation, $1.5 \pm 1.6 \mathrm{~kg} / \mathrm{m}^{2}$;' contemplation, $\left.1.4 \pm 1.4 \mathrm{~kg} / \mathrm{m}^{2}\right)(p<0.001$ for all). However, in the post-BS group, the maximum weight loss was observed among those that referred to be in the precontemplation stage $\left(24.6 \pm 6.7 \mathrm{~kg} / \mathrm{m}^{2}\right)$, whereas patients in more active stages claimed a lighter response to surgery (action, $14.9 \pm 7.4 \mathrm{~kg} / \mathrm{m}^{2}$; maintenance, $19.6 \pm 5.8 \mathrm{~kg} / \mathrm{m}^{2}$; $p \leq 0.016$ for both comparisons).

Data from the P-Weight questionnaire showed that patients in search for BS scored significantly higher in the four processes of change for weight management than individuals without obesity (Table 2). Subjects on the waiting list for BS also scored higher in processes related to weight consequence evaluation and emotional re-evaluation than subjects who had undergone BS, without differences in weight management actions and environmental restructuring processes. When participants who had undergone a previous bariatric procedure were excluded, a positive and significant correlation appeared between BMI and the score of the four processes of change for weight management (Fig. 2). When the post-BS group was added, correlations persisted with a lower correlation coefficient (EmR, $r=0.537, p<0.001$; WMA, $r=0.408, p<0.001$; EnR, $r=0.391, p<0.001$; WCE, $r=0.653, p<0.001)$. In addition, in this last group, BMI change was negative and significantly correlated with a decrease in score in three processes of change (EmR, $r=-0.423, p<0.001$; WCE, $r=-0.312, p=0.012$; WMA, $r=-0.179, p=0.153$, and EnR, $r=-0.355, p=0.004$ ) (Fig. 3).

Finally, the stepwise multivariate regression analysis showed that BMI and the S-Weight allocation were constantly associated with any of the four processes of change in weight management. In addition, the educational level and the degree with weight satisfaction also were related to EmR and WCE (Table 3).
Fig. 1 Distribution of the stages of change (S-Weight) in the three groups assessed in the study. $* p$ value $<0.05$ for the comparison between patients waiting for bariatric surgery obesity and patients undergoing bariatric surgery. ${ }^{\#} p$ value $<0.05$ for the comparison between subjects waiting for bariatric surgery and control group

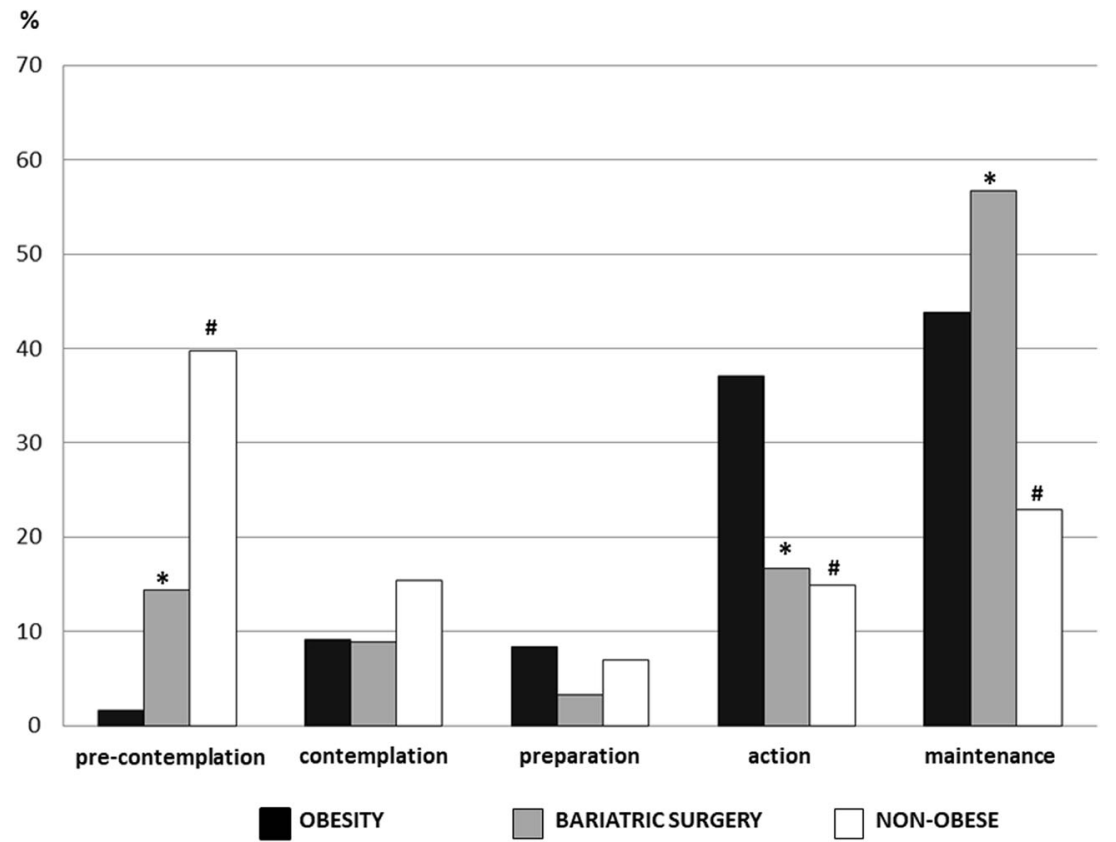


Table 2 Scores in the four Processes of Change in Overweight and Obese People (PWeight) according the three groups assessed in the study

\begin{tabular}{llllll}
\hline & $\begin{array}{l}\text { Obesity } \\
\text { group } \\
(n=251)\end{array}$ & $\begin{array}{l}\text { Bariatric } \\
\text { surgery group } \\
(n=90)\end{array}$ & $\begin{array}{l}\text { Control } \\
\text { group } \\
(n=201)\end{array}$ & $\begin{array}{l}p \text { value } \\
\text { Obesity versus bariatric } \\
\text { surgery group }\end{array}$ & $\begin{array}{l}p \text { value } \\
\text { Obesity versus } \\
\text { control group }\end{array}$ \\
\hline EmR & $81.2 \pm 11.7$ & $68.4 \pm 16.7$ & $53.9 \pm 16.6$ & $<0.001$ & $<0.001$ \\
WMA & $66.7 \pm 14.7$ & $65.5 \pm 15.5$ & $51.0 \pm 16.8$ & 0.494 & $<0.001$ \\
EnR & $56.4 \pm 18.4$ & $54.7 \pm 18.9$ & $38.6 \pm 16.1$ & 0.459 & $<0.001$ \\
WCE & $74.8 \pm 15.4$ & $58.5 \pm 17.9$ & $37.5 \pm 14.4$ & $<0.001$ & $<0.001$ \\
\hline
\end{tabular}

Data are expressed as mean \pm standard deviation. $E m R$, emotional re-evaluation; $W M A$, weight management actions; $E n R$, environmental restructuring; $W C E$, weight consequences evaluation

\section{Discussion}

To the best of our knowledge, this is the first study to establish that obesity is accompanied by a modifying behavioral stage, suggesting that people on the waiting list for BS are aware that a problem exists and are seriously thinking about overcoming it. This data arises against the extended belief that overweight people are lazy and lacking willpower about nutrition [27]. In addition, their positioning in the "action" and "maintenance" stages (the most advanced stages for weight management) relates to the engaging in overt and covert activities that attempt to modify problem behaviors related with weight excess. Our results seem to deny reality, in which most people with obesity do not continue with weight loss programs, and
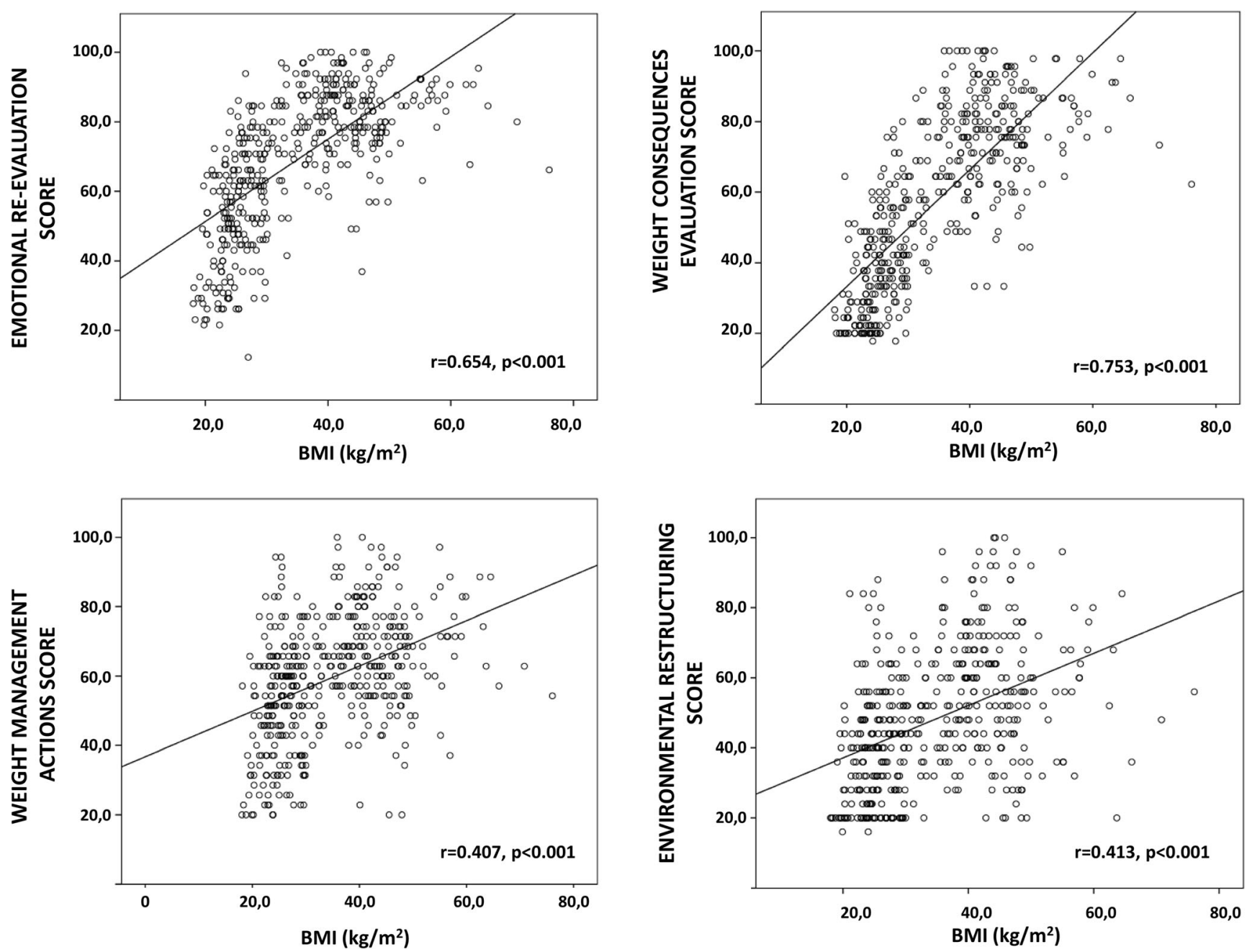

Fig. 2 Scatter plots showing the linear correlation between body mass index and the score obtained in the assessment of the four processes of change in weight management in subjects without a previous bariatric procedure $(n=452)$ 

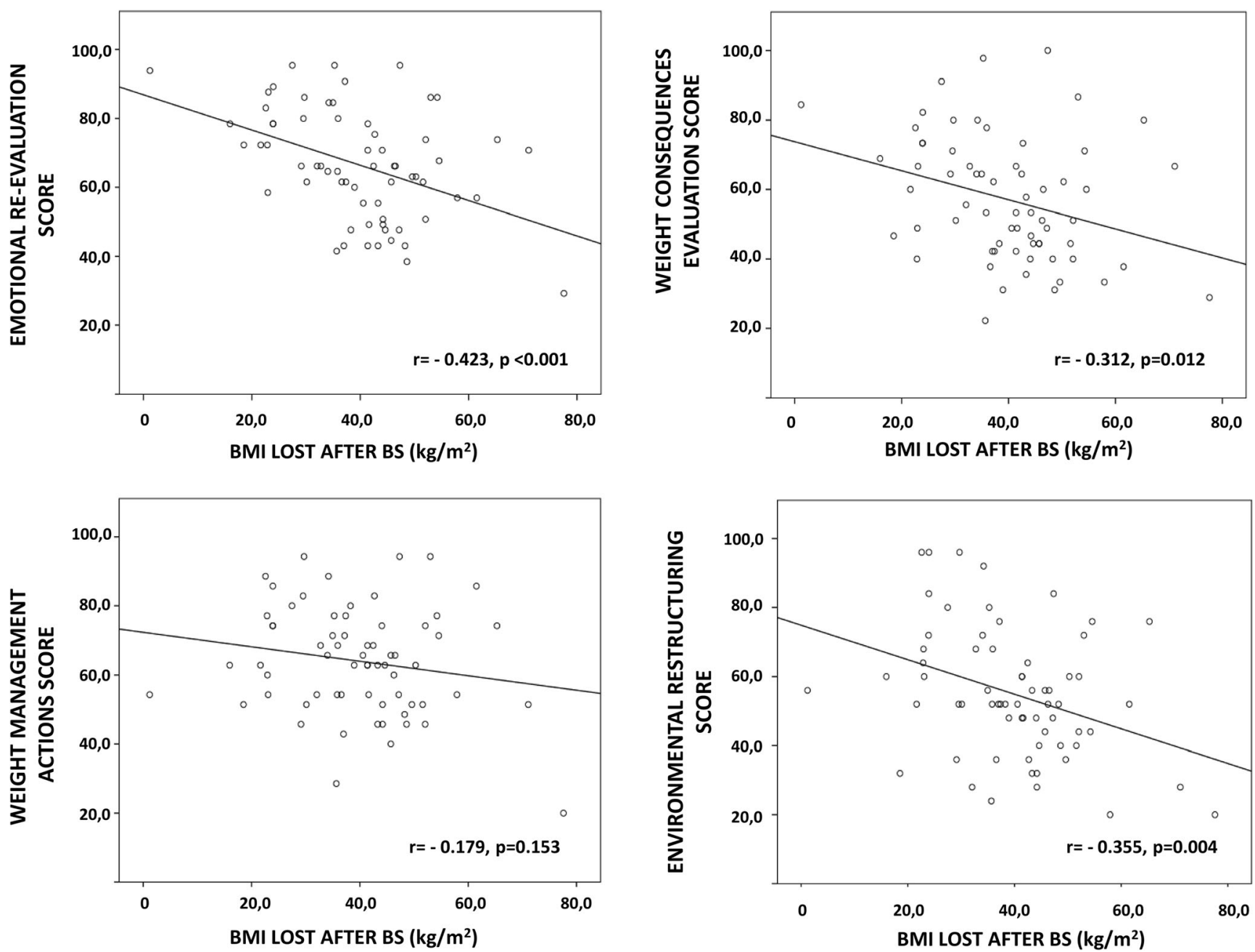

Fig. 3 Scatter plots showing the linear correlation between BMI loss after bariatric surgery and the score obtained in the assessment of the four processes of change in weight management $(n=90)$

only a few of those who do so actually lose weight. However, this outcome may be influenced by factors such as the requirement of compliance of all visits in the hospital, the close follow-up of the lifestyle behavior, and the demand to lose weight before undergoing BS. Therefore, it is possible that patients on the BS wait list were trying to present themselves in a favorable light [28]. Participants in obesity treatment programs describe several barriers such as lack of time, frustration from preceding unsuccessful weight-loss efforts, and the perceived cost of healthy foods [29]. Therefore, the way in which to transform favorable motivational stages into clinically relevant results is still a major obstacle for healthcare professionals taking care of subjects with overweight and obesity. Although there is no yet established the best technique of behavioral treatment, interventions require to be adapted to reflect the needs of the patient population and local context [30]. Individual and group sessions, in which participants are invited to bring along a partner if they wish, with patientcentered counseling techniques, and designed to teach key facts about diet and physical activity, together with the skills of action planning, problem-solving and self-monitoring [23, 31].

It has been suggested that motivational techniques may promote weight loss by increasing adherence to weight loss programs [11, 32]. The ability to assess the point at which subjects with obesity are ready to change may help clinicians tailor healthy interventions according to the patient's motivation and address retention in the setting of weight management. In this regard, the TTM proposes two interrelated domains for the adequate assessment of behavioral change: stages and processes [20,33]. "Stages of change" represents a motivational and constancy temporal trait that includes a whole spectrum of subjects with obesity, ranging from those without any intention to change their behavior in the foreseeable future to those who are working to prevent relapse and consolidate the healthy behavior $[13,20]$. So, the identification of the motivational stage of the patient with obesity through the S-Weight questionnaire before any therapeutic intervention seems mandatory to improve patient selection. This tool will recognize patients in the action stage in which 
Table 3 Stepwise multivariate regression analysis of variables associated with the four processes of change in weight management

\begin{tabular}{|c|c|c|c|}
\hline & Beta & $\mathrm{B}(95 \% \mathrm{CI})$ & $p$ \\
\hline \multicolumn{4}{|l|}{ Emotional re-evaluation } \\
\hline Weight satisfaction (from satisfied to dissatisfied) & 0.320 & $2.6(1.9$ to 3.3$)$ & $<0.001$ \\
\hline S-Weight (from inactive to active stages) & 0.313 & $3.8(2.9$ to 4.7$)$ & $<0.001$ \\
\hline BMI $\left(\mathrm{Kg} / \mathrm{m}^{2}\right)$ & 0.312 & $0.6(0.4$ to 0.8$)$ & $<0.001$ \\
\hline Education (from lower to higher education) & -0.078 & $-0.6(-1.2$ to -0.1$)$ & 0.028 \\
\hline Gender $(\mathrm{M} / \mathrm{W})$ & 0.014 & - & 0.678 \\
\hline Age (years) & -0.020 & - & 0.570 \\
\hline Gross incomes (from lower to higher income) & -0.021 & - & 0.610 \\
\hline \multicolumn{3}{|l|}{ Constant } & $<0.001$ \\
\hline \multicolumn{4}{|l|}{$R^{2}=0.760$} \\
\hline \multicolumn{4}{|l|}{ Weight consequences evaluation } \\
\hline BMI $\left(\mathrm{kg} / \mathrm{m}^{2}\right)$ & 0.554 & $1.2(1.0$ to 1.4$)$ & $<0.001$ \\
\hline S-Weight (from inactive to active stages) & 0.211 & $3.1(2.1$ to 4.1$)$ & $<0.001$ \\
\hline Weight satisfaction (from satisfied to dissatisfied) & 0.128 & $1.3(0.5$ to 2.0$)$ & 0.002 \\
\hline Education (from lower to higher education) & -0.086 & $-0.8(-1.5$ to -0.2$)$ & 0.013 \\
\hline Age (years) & 0.032 & - & 0.351 \\
\hline Gender (M/W) & -0.043 & - & 0.201 \\
\hline Gross incomes (from lower to higher income) & -0.045 & - & 0.258 \\
\hline \multicolumn{3}{|l|}{ Constant } & 0.297 \\
\hline \multicolumn{4}{|l|}{$R^{2}=0.598$} \\
\hline \multicolumn{4}{|l|}{ Weight management actions } \\
\hline S-Weight (from inactive to active stages) & 0.473 & $5.1(4.2$ to 6.1$)$ & $<0.001$ \\
\hline BMI $\left(\mathrm{Kg} / \mathrm{m}^{2}\right)$ & 0.191 & $0.3(0.2$ to 0.5$)$ & $<0.001$ \\
\hline Education (from lower to higher education) & -0.091 & $-0.7(-1.3$ to -0.1$)$ & 0.034 \\
\hline Gender (M/W) & 0.028 & - & 0.503 \\
\hline Gross incomes (from lower to higher income) & 0.017 & - & 0.733 \\
\hline Age (years) & 0.004 & - & 0.919 \\
\hline Weight satisfaction (from satisfied to dissatisfied) & -0.055 & - & 0.279 \\
\hline \multicolumn{3}{|l|}{ Constant } & $<0.001$ \\
\hline \multicolumn{4}{|l|}{$R^{2}=0.363$} \\
\hline \multicolumn{4}{|l|}{ Environmental restructuring } \\
\hline S-Weight (from inactive to active stages) & 0.323 & $4.1(2.9$ to 5.3$)$ & $<0.001$ \\
\hline BMI $\left(\mathrm{Kg} / \mathrm{m}^{2}\right)$ & 0.283 & $0.5(0.4$ to 0.7$)$ & $<0.001$ \\
\hline Gender (M/W) & 0.026 & - & 0.568 \\
\hline Age (years) & -0.016 & - & 0.727 \\
\hline Weight satisfaction (from satisfied to dissatisfied) & -0.050 & - & 0.361 \\
\hline Education (from lower to higher education) & -0.051 & - & 0.269 \\
\hline Gross incomes (from lower to higher income) & -0.052 & - & 0.269 \\
\hline \multicolumn{3}{|l|}{ Constant } & $<0.001$ \\
\hline$R^{2}=0.255$ & & & \\
\hline
\end{tabular}

$B M I$, body mass index; $M$, male; $W$, women we expect to achieve the higher percentages of weight loss. It does not make much sense to start lifestyle changes when the patient is in the pre-contemplation stage, where high drop-out rates will occur.

A weight loss program improves weight, but not for all subjects, which leads to frustration in both patients and professionals. In our study, the application of the S-Weight questionnaire identified that almost $25 \%$ of patients with obesity seeking BS had allocated themselves to the three stages of change that are related to the lack or only a small intention to change their behavior (pre-contemplation, contemplation, and preparation stages). While BS provides appropriate weight loss in most individuals (defined as $\geq 50 \%$ excess weight loss), 20 $30 \%$ of subjects with obesity who undergo bariatric procedures 
do not reach this target [34]. This failure is considered multifactorial and has been associated with factors related both to the healthcare center (experience of the surgical team, technical factors, preoperative patient education) and certain patient characteristics (age, gender, baseline BMI, and presence of comorbidities) [35]. However, these factors only partially explain the failure of the surgical option, and the insufficient weight loss postBS still appears as an unresolved clinical problem. As the BMI decrement in our study was higher in subjects who claimed to be in active stages, we suggest that the identification of the motivational stage through the S-Weight questionnaire may improve patient selection and help to develop interventions targeted to change this temporal motivational stage before surgical and non-surgical treatment options. On the other hand, in the postBS group, the maximum weight loss was referred by patients in the pre-contemplation stage. In this way, BS emerges as a good technique not only for improvement of body health but also for body satisfaction, reversing the states of change from action or maintenance to pre-contemplation. It is reasonable to imagine that patients nearest to their ideal body weight also have a better self-esteem falling in the pre-contemplation stage. Finally, it also should be pointed out that almost one-third of participants without obesity were recognized to be in the action and maintenance stages, reinforcing the idea that preoccupation with excess weight also affects subjects without obesity.

The processes of change complement the assessment of the stages of change by identifying the types of hidden and overt activities and experiences in which individuals with obesity engage when they attempt to modify behaviors problems [21]. The four freely correlated processes of change have shown adequate psychometric properties and an adequate internal consistency when were previously evaluated in clinical and community adult samples from Spain and the United Kingdom $[13,24]$. In this regard, our data showed that as BMI increased subjects engaged in a higher number of processes of change for weight management, indistinctly related to EmR, WCE, WMA, and EnR activities. In addition, the biggest auto-referred decrement in BMI was positively correlated with the activities related with the four processes of change. Therefore, the assessment of stages and processes of change in obese patients' candidate to BS may be helpful to health professionals to tailor interventions according to patient's needs. Different strategies should be applied to promote behavioral change and to engage patients to acquire or/and maintain healthy habits that have been proved to be effective in weight management [21]. Furthermore, to better BS results, some patients in the action stage could be prioritized to the detriment of those in pre-contemplation or contemplation stages.

Some limitations should be managed when evaluating the results of our study. As a cross-sectional study, we cannot draw a causal relationship between both motivational stages and processes of change for weight management and obesity, and the potential result cannot be assessed in the setting of a weight loss-related program. However, obesity is one of the main relevant health problems in the twenty-first century that has had frustrating outcomes in its non-surgical management; therefore, our data support the development of interventional strategies after considering the results of both questionnaires. Second, the motivation for change in those participants on the waiting list for BS can be influenced by demand, as BS requires some modification of behavior as part of the conditions to undergo surgery that could potentiate the positive results obtained in our study. Third, the maximum weight assigned to patients was sometimes reported by participants, and we are not able to determine whether the subjects responded sincerely and objectively to the questions that were asked of them. Therefore, a social desirability bias, as a tendency of survey respondents to answer questions in a manner that will be viewed favorably by other, cannot be ruled out. In addition, both questionnaires should be interpreted solely as evidence of the convergent validity of the scale and not as a measure for psychopathology.

\section{Conclusion}

In conclusion, the obesity epidemic has resulted in increasingly urgent calls for large-scale effective treatments and prevention policies to attenuate the physical and psychological consequences of excess weight [36]. The present study represents a step forward in seeking these treatment goals for subjects on the waiting list for BS who will be more receptive to weight lost interventions. Our data suggest that patients seeking for BS who are not in the action and maintenance stages may be at risk for suboptimal clinical outcomes after bariatric procedures. Consequently, whether health professionals initiate efforts to potentiate the patient's motivational development, a tailored medical approach resulting in sustainable weight loss may be reached, particularly in the long-term. In this way, we suggest introducing the assessment of stages and processes of change in new therapeutic strategies and encouraging people to advance through the motivational stages to effectively reduce weight and prevent weight regain. More research is needed to effectively evaluate the connection between both questionnaires and their definitive applicability, not only in subjects previous BS but also in individuals with obesity seeking for non-surgical weight loss programs.

Funding Sociedad Española de Endocrinología y Nutrición (SEEN) provided support in this research.

\section{Compliance with Ethical Standards}

Conflict of Interest The authors declare that they have no conflict of interest. 
Ethics All procedures performed in studies involving human participants were in accordance with the ethical standards of the institutional and/or national research committee and with the 1964 Helsinki declaration and its later amendments or comparable ethical standards.

Informed Consent Informed consent was obtained from all individual participants included in the study.

\section{References}

1. Upadhyay J, Farr O, Perakakis N, et al. Obesity as a disease. Med Clin North Am. 2018;102:13-33.

2. NCD Risk Factor Collaboration (NCD-RisC). Worldwide trends in body-mass index, underweight, overweight, and obesity from 1975 to 2016: a pooled analysis of 2416 population-based measurement studies in 128.9 million children, adolescents, and adults. Lancet. 2017;390:2627-42.

3. Yanovski SZ, Yanovski JA. Long-term drug treatment for obesity: a systematic and clinical review. JAMA. 2014;311:74-86.

4. Lecube A, Monereo S, Rubio MÁ, et al. Prevención, diagnóstico y tratamiento de la obesidad. Posicionamiento de la Sociedad Española para el Estudio de la Obesidad de 2016. Endocrinol Diabetes Nutr. 2017;64:15-22.

5. Srivastava G, Apovian CM. Current pharmacotherapy for obesity. Nat Rev Endocrinol. 2018;14:12-24.

6. Sumithran P, Prendergast LA, Delbridge E, et al. Long-term persistence of hormonal adaptations to weight loss. N Engl J Med. 2011;365:1597-604.

7. Evert AB, Franz MJ. Why weight loss maintenance is difficult. Diabetes Spectr. 2017;30:153-6.

8. Wadden TA, Sternberg JA, Letizia KA, et al. Treatment of obesity by very calorie diet, behaviour therapy, and their combination: a five-year perspective. Int J Obes. 1989;13(suppl 2):39-46.

9. Eldar S, Heneghan HM, Brethauer SA, et al. Bariatric surgery for treatment of obesity. Int J Obes. 2011;35(Suppl 3):227-41.

10. Adams TD, Davidson LE, Hunt SC. Weight and metabolic outcomes 12 years after gastric bypass. N Engl J Med. 2018;378:93-6.

11. West DS, DiLillo V, Bursac Z, et al. Motivational interviewing improves weight loss in women with type 2 diabetes. Diabetes Care. 2007;30:1081-7.

12. Schelling S, Munsch S, Meyer AH, et al. Relationship between motivation for weight loss and dieting and binge eating in a representative population survey. Int J Eat Disord. 2011;44:39-43.

13. Andrés A, Saldaña C, Gómez-Benito J. The transtheoretical model in weight management: validation of the processes of change questionnaire. Obes Facts. 2011;4:433-42.

14. Prochaska JO, Diclemente CC. Stages and processes of self-change of smoking - toward an integrative model of change. J Consult Clin Psychol. 1983;51:390-5.

15. Diclemente CC, Prochaska JO. Self-change and therapy change of smoking-behavior - a comparison of processes of change in cessation and maintenance. Addict Behav. 1982;7:133-44.

16. Prochaska JO, Velicer WF, Diclemente CC, et al. Measuring processes of change - applications to the cessation of smoking. J Consult Clin Psychol. 1988;56:520-8.

17. Greene GW, Rossi SR. Stages of change for reducing dietary fat intake over 18 months. J Am Diet Assoc. 1998;98:529-34.

18. Horwath CC. Applying the transtheoretical model to eating behaviour change: challenges and opportunities. Nutr Res Rev. 1999;12: 281-317.
19. Povey R, Conner M, Sparks P, et al. A critical examination of the application of the Transtheoretical Model's stages of change to dietary behaviours. Health Educ Res. 1999;14:641-51.

20. DiClemente CC, Prochaska JO, Fairhurst SK, et al. The processes of smoking cessation: an analysis of precontemplation, contemplation, and preparation stages of change. J Consult Clin Psychol. 1991;59:295-304.

21. Prochaska J, DiClemente CC, Norcross JC. In search how people change. Am Psychol. 1992;9:1102-14.

22. Romain AJ, Bernard P, Hokayem M, et al. Measuring the processes of change from the Transtheoretical Model for physical activity and exercise in overweight and obese adults. Am J Health Promot. 2016;30:272-8.

23. Gillison F, Stathi A, Reddy P, et al. Processes of behavior change and weight loss in a theory-based weight loss intervention program: a test of the process model for lifestyle behavior change. Int J Behav Nutr Phys Act. 2015;12:2.

24. Andrés A, Saldaña C, Beeken R. Assessment of processes of change for weight management in a UK sample. Obes Facts. 2015;8:43-53.

25. Andrés A, Saldaña C, Gómez-Benito J. Establishing the stages and processes of change for weight loss by consensus of experts. Obesity. 2009;17:1717-23.

26. Yumuk V, Tsigos C, Fried M, et al. Obesity Management Task Force of the European Association for the Study of Obesity. European Guidelines for Obesity Management in Adults. Obes Facts. 2015;8:402-24.

27. Ellison J. Weighing in: the "evidence of experience" and Canadian fat Women's activism. Can Bull Med Hist. 2013;30:55-75.

28. Bautista-Castaño I, Molina-Cabrillana J, Montoya-Alonso JA, et al. Variables predictive of adherence to diet and physical activity recommendations in the treatment of obesity and overweight, in a group of Spanish subjects. Int J Obes. 2004;28:697-705.

29. Staiano AE, Marker AM, Comeaux J, et al. Family-based behavioral treatment for childhood obesity: caretaker-reported barriers and facilitators. Ochsner J. 2017;17:83-92.

30. Gillison F, Greaves C, Stathi A, et al. 'Waste the Waist': the development of an intervention to promote changes in diet and physical activity for people with high cardiovascular risk. Br J Health Psychol. 2012;17:327-45.

31. Rosal MC, Ebbeling CB, Lofgren I, et al. Facilitating dietary change: the patient-centered counseling model. J Am Diet Assoc. 2001;101:332-41.

32. Goldberg JH, Kiernan M. Innovative techniques to address retention in a behavioral weight-loss trial. Health Educ Res. 2005;20:439-47.

33. Seals JG. Integrating the transtheoretical model into the management of overweight and obese adults. J Am Acad Nurse Pract. 2007;19:63-71.

34. Maggard MA, Shugarman LR, Suttorp M, et al. Meta-analysis: surgical treatment of obesity. Ann Intern Med. 2005;142:547-9.

35. Livhits M, Mercado C, Yermilov I, et al. Preoperative predictors of weight loss following bariatric surgery: sistematic review. Obes Surg. 2012;22:70-89.

36. Aronne LJ, Wadden T, Isoldi KK, et al. When prevention fails: obesity treatment strategies. Am J Med. 2009;122(4 Suppl 1): S24-32.

Publisher's Note Springer Nature remains neutral with regard to jurisdictional claims in published maps and institutional affiliations. 